\title{
The Translation of Mourid Barghthouti's Autobiography as a Cultural Encounter
}

\author{
Ayman Nazzal ${ }^{1}$ \\ ${ }^{1}$ Department of English language \& Literature, An-Najah National University, Nablus, West Bank, Palestine \\ Correspondence: AymanNazzal, Department of English language \& Literature, An-Najah National University, \\ Nablus, West Bank, Palestine. E-mail: anazzal@najah.edu
}

Received: June 2, 2018 Accepted: July 30, 2018 Online Published: September 1, 2018

doi:10.5539/ijel.v8n6p216 URL: https://doi.org/10.5539/ijel.v8n6p216

\begin{abstract}
I saw Ramallah, is an autobiography of Mourid Barghouti, a Palestinian writer and poet. It is an honest and accurate account of a Palestinian who could not adapt to the changes that have taken place during his absenteeism. It can also be considered a precise manifestation of the national and political identity of the author. It is about the abandonment and loss that Palestinians feel both in Palestine and in the Diaspora. I saw Ramallah is the type of literary genre that won the admiration of Edward Said, who considered it as, "one of the finest existential accounts of Palestinian displacement that we now have." The aim of this study is to explore translational problems and challenges of this autobiography into English by Ahdaf Soueif, the celebrated Egyptian novelist and critic. This study examines some of the translation strategies adopted by Ahdaf Soueif in handling the complexity posed by cultural-bound expressions since such expressions are bound to pose a real challenge for the translator. This study underlies the role of language in reflecting the realities of an entire community; all encompassed as facts, memories, imagination, and fiction.
\end{abstract}

Keywords: translation of autobiography, cultural encounter, non-fictitious genre

\section{Introduction}

I saw Ramallah, represents a cultural encounter about the author's attempt to reveal the countless problems he encountered on his return to his native country. It can be considered a manifestation of the national and political identity of the author himself and a genuine expression of the abandonment and loss that every Palestinian abroad or at home feels. I dare to say that, I saw Ramallah is a genuine account of the traumatic events and unforgettable experience of a person who has been away from his country for a protracted period of time. In this autobiography Mourid recounts his real feelings and sentiments then and at the timing of writing this literary genre and during his return through the bridge of the Jordan River Crossing which stands as a turning point or a cross gate at which one either enters into or departs from the West Bank. I Saw Ramallah chronicles the harsh circumstances which have led to the displacement of Palestinians and at the same time it is an accurate reflection of the tragedy of a people who have been harshly treated and abandoned due to unjust political and social circumstances imposed on them by their own occupier. The novelty of I saw Ramallah manifested itself in Mourid's continued feeling of displacement in spite of his return to Palestine. The primary purpose of this study is to underline some of the semantic, pragmatic, and possibly semiotic instances of the translation of this autobiography which bear witness to the dilemma of the majority of Palestinians. I chose this autobiography as a case study on account that it embodies some interesting pragmatic and semiotic issues worthy of investigation and study.

\section{Introduction to the Problem of Translating Autobiography}

Since part of this study involves looking at the challenges which have faced the translator of this autobiography, it is important first to provide some sort of an account on the origin of autobiography as a literal genre. An autobiography according to Anderson (2001, p. 50) is "a retrospective prose narrative produced by a real person concerning his existence, focusing on his life and his personality." As a literary concept, autobiography focuses on a writer's account of his or her own life. It underlies the retrospective narrative of the author's life and highlights the events and incidents which constitute and have a profound impact on one's life.

Other scholars like Lejeune (1989, p. 120) defines autobiography as, "The retrospective prose narrative written by a real person concerning his own existence where the focus is his individual life, in particular, the story of his 
personality". He claims further that autobiography is referential not fictitious. As a literary genre, Autobiography appeared in the Arab world before the appearance of Confession in Europe at the hand of Rousseau, which is considered the beginning of the art of autobiography in the West (Reynolds, 2001). In the Arab world the art of autobiography began as an oral form and then developed into a written and more complex genre. The first Arabic autobiography was "Al-Ayam" by Taha Hussein.

According to Taylor (2014), autobiographical translation entails precision more than other forms of literary genres. She claims that the primary focus of autobiographical translation lies not only in accounting for the message but also for the meta-message involved in the translation of certain expressions. Other scholars like Hatim and Mason (1990) have underscored the important role the semiotic dimension plays in the translation process taking into account all contextual and textual elements interacting with each other to produce a meaningful message.

Most translation studies have focused on prescribing translation strategies to account for various genres to fully account for whatever problems come in the way to accomplish the act of translation. While such an attempt by itself is adequate on a limited scale, it may not constitute the optimal attempt to account for the act of understanding since such an act must precede any act of translation. One of the challenges that have faced the translator of this autobiography is that relying on a single approach is not adequate to fully account for the translation of the events and incidents in this autobiography and thus the optimal approach has to be a multidimensional approach to provide an adequate translation of cultural expressions. According to Bell (1991) all words have both denotative and connotative meaning and by virtue of that the approach which the translator relies on has to be adequate enough to account for all meaning-bearing features in any language expression. Indeed, the most insightful conclusion that can be drawn from this particular study is that the act of translation cannot be precisely accurate unless the contextual forces and other meaning-contributing forces are taken into account. Since a great deal of the material in this autobiography is culture-specific and replete with emotive expressions, the translator could not always resort to the literal or denotative meaning to account for other important dimensions of meaning. Even appealing to Semantics as a core linguistic component cannot always be adequate to account for the meaning embedded in some culture-bound expressions on account that such expressions do not always adhere to semantic rules. Their meaning cannot be captured by appealing to their denotative meaning and; therefore, paying close attention to pragmatic/semiotics aspects in certain instances can be an optimal way to adequately account for such hidden meanings.

Another important challenge that appears to constitute a real constraint to the translator is that the perception of language and its role vary cross-culturally. Unlike other cultures, language in the Arab culture has a multiple function and it is not seen or regarded as a means of communication solely. In fact, the perception which most Arabic speaking individuals hold of their language is that it is multi-functional i.e. this multiplicity according to Chejne (1965) and Zaharana (1995) manifests itself in their enactment of the linguistic code whether in social interaction or in any literary genre and by virtue of that language to the majority of Arabs is considered as "a register of their experience and achievement." To illustrate this multiplicity further and its consequences on any intercultural communication encounter, Cohen (1987) attributes the breakdown of communication between Americans and Egyptians to the differences in their language perception and their use of certain communication strategies and thus the role of language for each group appears not only distinct but also calls for the performance of certain functions which obviously exceeds the mere function of language as being a means of communication. Having said that, then one can deduce from the text that the narrator is very much conscious of such multi-functionality of the role of Arabic language and as a result of that he acted accordingly.

The concept of "emotiveness", appears to be operative in this narrative. In my opinion, "emotiveness" can be considered as a manifestation of such multiplicity and can potentially constitute one of the real challenges which have faced the translator in capturing the associative or connotative meaning of some of the expressions in this autobiography. It appears that some of the cultural expressions in this autobiography contain a high level of emotiveness embedded in the connotative meaning of such expressions and usually invoked by the text receiver (see, Mahasneh, 2016). The concept of emotiveness appears to be of great significance particularly when translating from Arabic into English since the intended meaning of certain expressions may reside in the social context rather than in the linguistic code itself or embedded in the associative meaning of the object referred to and usually invoked by the text receiver (see, Bronislava, 1987, quoted by Mahasneh, 2016).As Mahasneh (ibid) claims, emotiveness is a pervasive aspect in Arabic language discourse where certain expressions are bound to arouse certain feelings of joy, sadness, anger or excitement in the text user or receiver.

This study underlies some of the challenges that have confronted the translator in her act of translating such genre. The analysis of the excerpts cited in this study underlies the assumption that relying on the traditional view of 
semantics would not do us any service and falls short of adequately accounting for the metaphorical and non-metaphorical aspects or culture-bound expressions. Some of these challenges range from semantic to pragmatic/ semiotic related issues of great importance. It appears that not being literate in the local culture has impacted immensely the translator's rendition of many instances which have made her translation semiotic-ally and pragmatically imprecise. More importantly it is abundantly clear that translating such type of genre requires that the translator be aware of the pervasiveness of emotiveness in Arabic language and the extent to which such a phenomenon has bearing on the perception of the text user and receiver.

\section{Exploring Importance to the Problems of Literary Translation}

When dealing with a literary text, the translator has to tackle the question of subjectivity and be able to distance herself from the preconceived notions and the worldview which he or she unconsciously relies on to formulate any type of interpretation of any concept. Voloshinov/Bakhtin's concept of "hetero-glossia" is a confirmation of the ideological nature of the sign and the consequences of that on the act of translation. They believed further that "the linguistic sign is open to different orientations and evaluations in the social world" (quoted by Mesthrie et al., 2000, p. 321).This means that any translator is bound to interpret messages based on his/her personal frame of reference or at least is likely to be induced by his background knowledge and that such a rendition of anything is destined to invoke other adequate rendition of the same expression. It is therefore interminable process and subject to various interpretations. Some translation scholars like Terry Eagleton (1996), cautions against the consequences of the translator's biases in accomplishing this task. Eagleton has remarked that "ideologies like to draw rigid boundaries between what is acceptable and what is not, between self and non-self, truth and falsity central and marginal, surface and depth.”(1996, p. 115).

In addition, the translator has to deal with another challenge which deals specifically with the problem of untranslatability of some literary texts on account that uncovering the intention of the text and that of the writer's is in and of itself an extraneous task to accomplish and undermines the translator from being able to provide an adequate translation for any expression. Such a state of affairs has prompted Bassentt (1991) to relate the problem of untranslatability in the process of translating literary texts to the subjective meaning that can be interpreted differently. This shows how the act of translation renders itself as multi-dimensional act, i.e. an act where capturing the denotative and connotative pragmatic aspects in both the SL and TL become of great significance to the overall translation process.

Boushaba (1988) claims that finding a connection between the meaning of the text and the author's vision of life can potentially be instrumental in reading the text objectively. By virtue of that, uncovering the intention of the author can be a real challenge unless the translator makes a concerted effort to pay attention to both denotative and connotative meaning of the text and relate them to the author's personal experience and worldview.

According to Carbonell (1996) meaning is both culture and context-bound. As a consequence, it can be fully captured if and only if a translator incorporates a multi-dimensional approach to account for multilayer interpretations instead of looking for equivalence since linguistic utterances can be interpreted differently as a result of the contextual forces at work as well as the social background of the translators involved in the act of translation. Therefore, the linguistic 'sign' is not the problem but rather the elements which have great bearing on the outcome of any act of translation of any linguistic sign. In my opinion, it is a combination of several factors which conspire together to produce a rendition which always invoke other responses pertaining to the initial rendition (Nazzal, 2012).Some of these elements are contextual and textual along with the intervention of the social background of the human agency (Albzour, 2016). Variation in the act of translation is something inevitable by virtue of these elements working together consciously or unconsciously.

\section{Describing Relevant Scholarship to Culture and Translation}

Many scholars acknowledge the impact of one's culture and beliefs on the perception of the speakers of a particular linguistic system and whether consciously or unconsciously such influence ultimately impacts the role of the translator in search for equivalence (Dweik\& Suleiman, 2013; Whorf, 1956).

Since an important component of culture is usually expressed through language, then translation becomes highly significant. It is not too hasty to claim that while language appears so systematic and rule-governed, culture usually manifests itself in a kaleidoscopic fashion which makes it highly difficult to account for. By and large, culture manifests itself in various modes. These modes are destined to be interpretive and communicative too. In inter-cultural communication encounters, participants can experience such cultural differences clearly when they engage one another in an ordinary verbal exchange. They frequently misconstrue each other's messages when they interpret their communicated messages based on their respective native-like frame of reference. This seems to coincide with the astonishment expressed by Milton Bennett when he made the following insightful comments 
concerning the fragility of such encounters:"How do people understand one another when they do not share a common cultural experience.”(1998, p. 1).

The relation between culture and language is so intricate that makes the task of sorting them apart highly inconceivable, if it is not implausible. Such intricacy can be exemplified by drawing on Clifford Geertz's(1973) concept of "thin versus thick description" which he makes in his book, The Interpretation of Cultures, as an analogy for us to capture highly invaluable cultural nuances which are replete with meanings. For instance, he claims that the distinction between $a$ wink which signals a greeting gesture and the same gesture used as a sexual advance does not lie in the performance of the mechanism involved in the wink itself but rather in our interpretation of the context in which such a wink occurs. Geertz (ibid) calls such an illustration 'thick description' since it requires that the ethnographer be a keen observer and be able to find some correspondence between the social action and the linguistic sign which stands for its meaning.

The act of translating an autobiography resembles that of 'thick description'; it is clearly grounded in its local culture. The words expressed by the narrator are part and parcel of the culture it epitomizes. Understanding the meaning of words is contingent upon the translator's being literate in the local and domestic culture of the narrator of this autobiography. Language is ultimately indexical and in order to account for such function, the translator has to act and think like an ethnographer. This seems to be consistent with Erikson's views on the role of language and its relation with culture.

"A certain culture produces the language that they need: the language becomes a tool of thought and culture of a people can only be studied and analyzed through their language" (Erikson, 2009, p. 5).

Part of the difficulty of translating autobiography is that its language is replete with culture-bound expressions and requires the translator to be able to encode the relationship between the author and the meaning of the words he/she enacts in this narrative

Culture-specific expressions consist of proverbs, formulaic utterances, verses, historical incidents, beliefs, contexts, tastes and terms which are part and parcel of a particular culture. Culture-specific concepts are culture-particular which imply that they may or may not have equivalents in the target language. Different translation scholars have approached this subject with different views. Mona Baker (1992) for instance has dealt with various types of equivalence to account for culture-specific expressions on account that there is a variety of cultural and linguistic factors which influence equivalence. She claims that translating culture-bound expressions constitutes a real challenge to the translator particularly when the languages involved are linguistically and culturally are unrelated such as Arabic and English. Therefore, translators should be sensitive to both cultures bearing in mind that they should convey the message along with the force embedded in the same message.

Other scholars have provided some insightful taxonomy to account for such expressions. For instance Carter (1998, p. 34) makes an insightful dichotomy between two kinds of vocabulary words. The core vocabulary component is frequently used in communication with foreigners since it is not culture-bound and by virtue of that it can be translated similarly in all contexts and cultures. However, the non-core component is culturally context-bound. It is usually translated from one culture to another. The translation of the word "bridge" and "stranger" is an excellent illustration of how the translator has overlooked the other important semiotic /pragmatic dimension associated with the meaning of these two words.

The findings of studies on culture-bound expressions such as idioms and formulaic expressions (Nazzal, 2017) point out that the difficulty which translators encounter in accounting for their translation stems primarily from their being part of the 'marked' rather than unmarked category or non-canonical rather than canonical linguistic forms in any language. Thus translators should have adequate knowledge of both SLC and TLC in order to deal with cultural differences and narrow the cultural gaps between them.

\section{Methodology}

The methods used in this study consist of a citation of a set of excerpts taken from the autobiography itself deemed worthy of investigation on account that such excerpts speak highly of the person concerned and the culture to which he belongs. In addition, the excerpts cited in this study chronicle cultural encounters with some important events in the life of Mourid and his own community.

\section{Discussion of Data Analysis of Culturally-Bound Expressions}

The given text is different from other fictitious genres in the sense that it has a very strong emotional appeal and a factual content. There is no doubt that there are several dimensions that have to be taken into account in this process such as the communicative, pragmatic and emotive dimensions. In this commentary, I focus on some problems encountered in translating the given text from a multi-dimensional point of view. Actually, there are so 
many factors that any translator has to take into consideration when translating from the source language, here Arabic, into the target language, in this case English; these factors are related to the genre and text type, the skopos of the translation, the setting of the translated text, i.e. where to be published, the source text producer, the readership, etc, and by virtue of that, the translator has to be a bicultural person to play such role.

In this particular component, I cite some of the translated expressions from Mourid Barghouti's autobiography "I Saw Ramallah" and point out some of the challenges the translator came across and point out some of the translation strategies the translator opted for to explain the intended meaning. Some of the challenges though are inevitably justified by virtue of the fact that the translator cannot possibly be an expert on the highly subtle nuances of the Palestinian culture. According to Taylor, 2014; Hatem and Mason, 1990; Boushaba, 1988; Gorjan, 1970) a translator has to be versed in the target culture in order to fully and adequately account for its meaning. Some of the illustrations that I cite are culture-bound expressions which have a lot of significance and require a great knowledge of the local culture.

\subsection{Deletion as Translation Strategy}

By and large, untranslatability is an instance which usually confronts the translator where he/she deems it appropriate not to translate specific expressions or utterances for a set of reasons. The following is an instance in which the translator finds it more appropriate not to translate culture-specific expressions for several reasons one of which is the lack of lexical equivalence in the TC or the difficulty of conveying the precise meaning of such expressions to the TC:

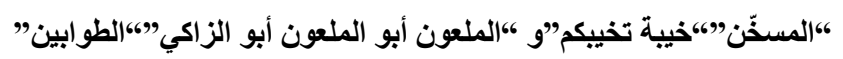

According to Teilanyo (2007, p. 15) culturally-bound expressions can be a real challenge for the translator if the target language lacks an adequate equivalent, then the text is not translatable. He claims that "the difficulty arises from the problem of finding adequate target language equivalents for terms conveying culture-sensitive notions in the source language as a result of the fact that the two languages have different meaning subsystems and cultures".

One can acknowledge that these words are culture-specific; and they can only be understood easily by the speakers who belong to the same culture. However, I think the translator's decision to avoid translating them is unjustified for various reasons one of which is that she could have provided a brief paraphrase to capture the cultural significance of such expressions since they are about an important and highly popular dish. According to Jacobson (1959) all cognitive experience is conveyable in any language by resorting to loanwords or loan translation and neologisms strategies. One does acknowledge that Arabic and English are linguistically different, but still these culture-bound expressions or colloquial words can be made intelligible to the target audience by either providing a paraphrase or descriptive account since their meaning is highly important and reflects a great deal about the creativity of making food by relying on the produce of the country. In fact, I am willing to argue that the translator could have provided a brief description of the type of food the above excerpt contains since it reflects a great deal about the local culture that the narrator belongs to and the taste of the indigenous people.

The translator's adoption of such a translation strategy might have constituted a tactful act provided that no harm is being inflicted on either concerned parties. Resorting to such a strategy has certainly safeguarded the translator from any unseemly criticism but I think it is unjustified for the same reasons I have provided above since they can be made intelligible to the target audience if the translator has made some extra effort to convey the meaning of such important culture-specific expressions. It is in such instances where the creativity of the translator emerges and becomes visible and communicative. Thus, since the cultural distance between the source language and the target language is so large and multi-faceted, the translator has to intervene in order to bridge this cultural gap, especially if we know that the expression is culture-specific in the sense that the concept is found and embedded in one culture and its signifying system but not in another culture.

In the following excerpt, one can note that the translator has confined herself to the semantic meaning of most of the excerpt and left several words without translation for various reasons one of which is that some of the words are culture-specific and have no equivalents in the TT and therefore she deemed it more appropriate to overlook such culture-bound words. So deletion appeared to be an optimal strategy in this particular context and it may be justified on such basis. The real challenge which confronts the translator is to account for the translation of culture-bound concepts which have no equivalence and can't be expressed in the target language. For example the following is an instance where the translator deems it more practical to avoid translating some culture-specific words which have no equivalence in the target culture:

“نهضوا بقاماتهم وقنابيز هم وحطّاتهم البيضاء ووجو ههم على الفور” 


\section{"They stood up in front of me in their bodies, their clothes, their white headdresses, their faces. They stood up as though they had not died."}

The words قنابيز هم وحطاتهم constitute a real problem since these words are culture- specific expressions. The translator provided their semantic equivalence for a couple of reasons: first there is no correspondence to these words in the TTC, so she chooses equivalents that have the same function in the TT, even though both "headdresses" and "clothes" don't capture the accurate and precise meaning of the Arabic words قنابيز) (.Since such costumes are folkloric and reflect the cultural style of clothing. At the same time one can note that the translator didn't translate the words " and settles for using the pronoun "they" at the beginning of the TT.This may have some effect on the overall meaning of the entire excerpt. She could have used the word 'costumes' instead of clothes to convey to the target audience the type of clothing they were wearing pointing out the cultural costumes; therefore, opting for deletion as a translation strategy might not have been the optimal strategy since by resorting to such strategy, she did not adequately convey the intended meaning of such expressions.

Instances like these are frequent occurrences in this autobiography where such expressions may have equivalents in the target language, but simply not lexicalized. Such challenges are inevitable occurrences in translating a genre replete with emotiveness and are likely to invoke different emotion and feelings in both readers and receivers. In the following excerpt, one can note that she translates some colloquial expressions and leaves other expressions without any rendition:

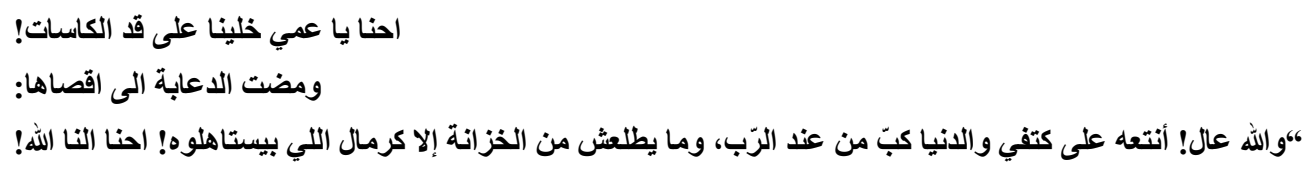

The translation is:

\section{Here Abu Hazim refused it for me.}

"A glass is good enough for me!" He carried on:

"I carry it on my shoulder while God's rain is spilling down on us, and it never leaves its cupboard except to honor those who deserve it! I put my trust in God."

In contrast with previous example or instance of deletion, one can note that the translator resorted to the deletion of some words in the above excerpt on account that the target audience may not grasp the intended meaning of the expressions اله اله عالin the above excerpt and in which the translator does several things to account for the translation of the above excerpt. First, she deletes the colloquial expressions," which is used to express the dissatisfaction and frustration of the person carrying the load in the rain on account that she could not find an appropriate equivalence for the ST terms. On the other hand, she adequately translates the colloquial Palestinian word " "ifo its semantic meaning "carry". She could have translated the idiomatic/formulaic expression,”" “و الدنيا كبّ من الرّب", semantically and pragmatically with its TT equivalence, by citing the English equivalence: "it is raining cats and dogs", to capture its full intended meaning in the ST and in TC, but she chose not to do that. She translates the phrase "حنا النا اللها|"،, adequately since she captures the intended meaning of such expression by making the force and function of ST clear in the TT. When one reads the ST and its rendition, one is inclined to feel that there is some important connotative meaning missing in the translator's rendition. I do attribute this to the unintelligibility of some of the expressions communicated between the guests and the host.

\subsection{Opting for the Literal versus Semantic Meaning}

This is an instance where the translator finds herself oscillating between two different levels of meaning one of which may prove unintelligible to the target audience and by opting for such an option a great deal of loss is being committed by the translator. One such impediment which faces the translator is whether to appeal to the literal or semantic/conceptual meaning to fully and adequately account for the intended meaning since ordinary language is often used to describe many cultural customs where a literal translation would fail to account for the proper meaning. Such gap usually manifests itself either in the exchange of a message in intercultural encounters or in the act of translation. The following is an excerpt which underscores one of the challenges that has faced the translator in accounting for the appropriate rendition:

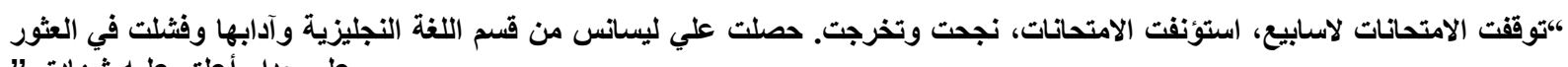

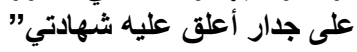

"The examinations are suspended for weeks. The examinations resume. I graduate. I am awarded a B.A. from the Department of English language and Literature, and 


\section{I fail to find a wall on which I hang my certificate"}

The translator in the above excerpt has successfully provided the literal/ conceptual meaning of the whole excerpt; however, she has refrained from providing the intended /connotative meaning of the following line in the same excerpt:“ I fail to find a wall on which I hang my certificate”. In this particular excerpt the narrator reveals his desire to return back home and to celebrate his graduation with his family and relatives but unfortunately he was deprived of such a right due to a host of political and other compelling reasons which prompted him to use the metonym to convey his intended meaning. The translator's rendition didn't convey the intended meaning of the metonym and the emotiveness embedded in this excerpt fearing that the target audience may not grasp it; however, she could have done some elaboration or a footnote to explicate and convey what the narrator intended to convey in saying I fail to find a wall on which I hang my certificate in the above excerpt.

There is no denying that when it comes to the interpretation of culture, meaning is context bound. This has been discussed by so many scholars from various disciplines. Dressler and Beaugrande (1981) claim that not only context in which a particular utterance is produced but also the situation appears to have great influence on the meaning of that utterance. In light of this, the meaning of the abovementioned expression depends upon the context in which it occurred and the relevance of the situation to the text. This seems to be consistent with other scholars like Derrida (1980) who has made similar comments concerning the contingency of meaning on account that meaning changes constantly from one context into another. The fact of the matter is that the translator has to pay attention to the Skopos of such an expression to accomplish the task. Conveying the intended meaning to the target audience is a key component of the translator's role.

While semantic and literal meaning is supposedly similar, Newmark (1981) claims that semantic translation is the closest to literal translation except that it pays great deal of attention to the social context of the source text whereas literal translation confines itself to the literal meaning of words.

"Communicative translation attempts to produce on its readers an effect as close as possible to that obtained on the readers of the original. Semantic translation attempts to render, as closely as the semantic and syntactic structures of the second language allow, the exact contextual meaning of the original."(Newmark 1981:39)

In the following excerpt, one can note that the translator paid more attention to the literal meaning of this excerpt more than to the semantic and pragmatic/dimension of what has been said and narrated and by virtue of that the "illocutionary force" or the intended meaning of the utterance is being lost..

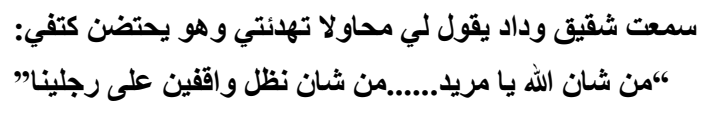

The translation is:

\section{"Calm down, so that we can stay on our feet... for God's sake"}

I think the translation of the above excerpt has to be done in light of the context and situation in which this particular excerpt occurred. Staying on feet is not meant physically, but rather to be able to endure and move on in the face of the tragic incident of the loss of Mourid's closest friend. The narrator was in a terrible state of mind standing at the grave of his closest friend, Naji Al-ali, the Palestinian cartoonist, eulogizing him. He was in a state of shock and despair of the political situation and other circumstances. The cultural connotation of this phrase is to keep strong, steadfast, and calm in the face of difficulties. The translator renders it into its literal equivalent attempting to keep the force of the TT as they are in the ST provided that such a phrase, "stay on feet" or "stand on feet" may have the same connotative meaning in both cultures.

Another problem that the translator has encountered while translating cultural terms is deciding the suitable strategy and adopting the appropriate technique of translation. Cultural words require a cultural background to be properly understood and therefore pose a real challenge to the translator. Those problems result from a number of linguistic phenomena, including the different semantic range of the cultural words in both TT and ST, or the absence of the cultural concepts in the target language ( Dweik and Suleiman, 2013).The translator's rendition of the following words"طابون، مسخن،ين خرطماني و غير ها:seems not to be the optimal translation since it did not capture the intended meaning. For instance one can note that the translator opted for a translation strategy which is inappropriate to account for the pragmatic and socio-pragmatic equivalences for culture-bound expressions: Some of the following words got deleted likeينين خرطمانeven though she could have translated such words into

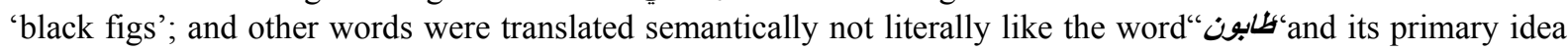
is being lost”"طابون، مسخن،تين خرطماني وغير". Moreover, their pragmatic equivalences are overlooked in the TT.For example, طابون is translated into "oven", and مسنين is translated into "food". She could have paraphrased or provided a descriptive account of the intended meaning of such expressions since they are representative of 
the local culture.I think accounting for the semantic dimension over the literal one is not the optimal strategy in this particular situation since by doing that a lot of connotative meaning has been sacrificed

Let's take another example to explicate the challenge which has faced the translator in her rendition of some key lexical items. For instance the translator translates the word"الغريب|"in the ST into "the stranger" which doesn't convey the pragmatic equivalence which is its intended meaning. In fact, the author of the ST means by "“الغريب: the displaced person who doesn't come to this place willingly. Therefore, the literal translation of this word doesn't reflect the accurate image of the original word " Consequently we note that the connotative/associative dimension has been sacrificed at the expense of other less important aspects. This particular instance reminds one of the implications of Voloshinov/Bakhtin's concept of "hetero-glossia", which states that, "the linguistic sign is open to different orientation and evaluations in the social world", (qtd by Mesthrie et al., 2000:321).The translator's rendition of this word,"الغريب"did not convey its intended meaning for the target audience.

\subsection{Opting for Semantic versus Pragmatic}

The following are some of the instances which frequently occur in the translation of this autobiography and in which the translator has to make an adequate choice between appealing to the semantic or pragmatic meaning in order to provide an adequate account for the intended meaning or the "illocutionary force" of the utterance. Scholars like Faiq (2004) claimed that culture is the attitudes towards the world, towards the events. Such ideas have manifested themselves in the translator's rendition of this autobiography. She could not possible cover all nuances of meaning which can be conjured up by the text's reader or receiver. As a consequence her rendition appears to have missed some meaningful aspects. The following excerpt is an example of Soueif's rendition of the following expression:

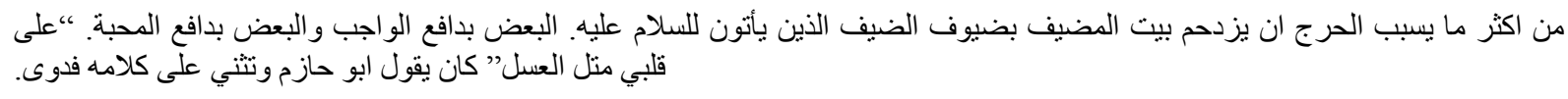

It is very embarrassing when the home of your host is filled with your guests. Abu Hazemsaid: "It's like honey on my heart", and Fadwa seconded him."

Her rendition for the above excerpt has obviously accounted for the denotative and conceptual meaning rather than the intended meaning where the "illocutionary force" lies. The word bridge is another illustration where the translator fails to capture its intended meaning. She translated it literally without paying any attention that this particular word conjures up lots of memories in the minds of most Palestinians. She did not account for the emotive senses involved in the mind of the narrator when he used such word. She just translated it literally and denotatively without showing the emotiveness which this word could have invoked in the hearer as well as the receiver of this word. No wonder why the narrator uses different names to refer to the same 'bridge'.

As a matter of fact, the concept of 'sign' for Voloshinov and Bakhtin is different from that of Saussure since the two scholars associate the analysis of texts with 'a conflict understanding of society (qtd by Mesthrie et al (2000). Voloshinov's conception of the 'sign' has provided some sort of a paradigm shift, by reversing the Saussurean's priority of langue over parole; and by virtue of that the 'sign' can't be interpreted outside the social interaction of human beings. Such views appear to relate directly to the type of discrepancy in the translation of $I$ saw Ramallah which the translator has run into with the translation of the word stranger. This particular word conjures up more associative meaning than what the translator provided and as a result of that she missed some important connotative meaning since capturing the associative meaning embedded in this word obliges the translator not only to be part of the indigenous community but also to be part of those who have gone through the experience which Palestinians living on the West Bank endured painfully.

Capturing the complete meaning of these two terms (the word "bridge" and "stranger") requires the translator to perceive the emotive aspects ingrained in these terms and the social and political contexts which are part and parcel of the whole context since the very act of mentioning them brings a lot of past/ present memories in the mind of those who had lived and experienced the events associated with these two terms. Not being able to capture the real and complete meaning does not place any blame on the translator's competence or linguistic ability but rather has to do with the translator not being part of 'the speech community' whose members share a set of beliefs and values and abide by the same frame of reference and therefore they are destined to perceive the world with the same perception since they have gone and lived the same experience (see, Hymes, 1972; Labov, 1972a).

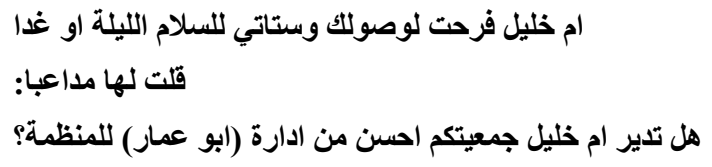




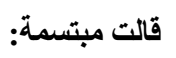

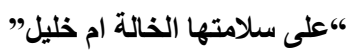

The translation is:

"Umm Khalil is very glad you're here. She'll come to see you tonight or tomorrow."

"Does Umm Khalil run your organization better than Arafat runs the PLO?" I joked.

"Umm Khalil is just fine"

In this particular instance the expression "على سلامنها" is frequently used in Arabic to refer to a person known for being kind and cooperative and lives up to his/her community obligations and duties and does his/her best to serve others.

By translating this Arabic expression into English as "just fine", the translator's rendition implies two different meanings one of which is needed to capture the intended meaning in the above statement. Moreover, she did not adequately reflect ST message and function when she translated it into "just fine" since the first impression perceived by the listener is that the subject (Umm Khalil) is not feeling well or is having some sort of health complications rather than that she is reputed to be a cooperative woman.

The translator's English rendition "she's just fine", can be translated as هي بخير which departs from the intended meaning of ST. In such cases, it is preferable to give more details in order to make TT explicit.

We note that neither the "sskopos" of the above excerpt has been treated adequately nor has the translator taken into account the audience of the target text. An adequate elaboration on the semiotic dimension of what the expression is intended to mean would have done great justice to all concerned parties.

\section{Results \& Conclusion}

This preliminary study has pointed out some of the challenges that the translator has encountered in her rendition of some culture-bound expressions. The initial findings seem to indicate that such challenges are demanding as the ones found in any literal genre and that the most subtle ones are the ones related to culture since they require a multi-dimensional approach to account for their understanding and then translation. In fact this preliminary study has focused primarily on such culture-bound expressions. However this autobiography is replete with emotiveness and rhetorical devices such as metaphors, personification and metonyms which appear to be as challenging as culture-bound expressions. It also appears that after analyzing some of the data, the translator has used various strategies to account for the translation of this autobiography. While the choice of a particular translation strategy is highly important, the optimal approach that appears to be fit is a multi-dimensional approach since falling back on the literal or relying on the semantic approach only would not be the optimal one. Finally, the translator uses various strategies in translating culturally-bound expressions which also include colloquial terms. Culture continues to pose a real challenge for the translator on account that Arabic and English are culturally different. Conveying the emotiveness ingrained in some of these culture-bound expressions proves to be an awesome task to be tackled. 
Table 1. Some translation strategies used by the translator

\begin{tabular}{|c|c|c|}
\hline Strategy & English translation (TT) & The original sentence (ST) \\
\hline Omission & $\begin{array}{l}\text {..Thirty years ago, From Amman I went to } \\
\text { Cairo and back to college. I was in my } \\
\text { fourth and final year at Cairo university }\end{array}$ & 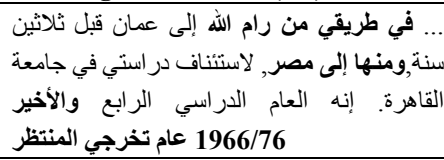 \\
\hline Dialect Standard English rendering & $\begin{array}{l}\text { Mourid! Mourid! War has broken out. } \\
\text { We've brought down twenty-three planes. }\end{array}$ & 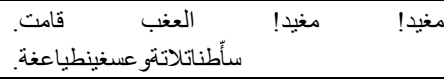 \\
\hline Multiple translations for one word & Displacement-exile-estrangement & 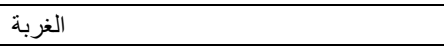 \\
\hline Paragraph omission & Omitted & 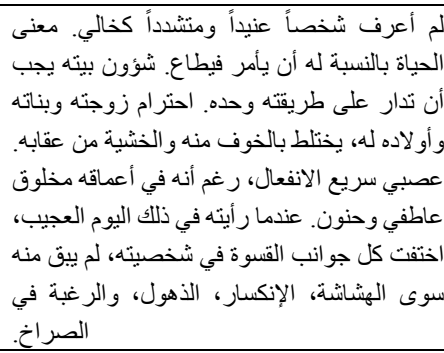 \\
\hline $\begin{array}{l}\text { Palestinian dialect standard English } \\
\text { rendering }\end{array}$ & $\begin{array}{l}\text { "This is what they printed with your poem } \\
\text { in al-Safir. I drew it again - bigger. For } \\
\text { you and Radwa and Tamim" }\end{array}$ & 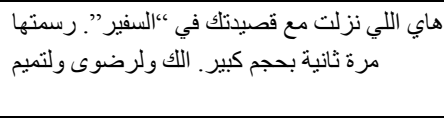 \\
\hline
\end{tabular}

\section{References}

AlBzour, B. (2016). Conceptual translation script theory over equivalence theory. International Journal of Applied Linguistics \& English Literature, 5(5).

Anderson, L. (2001). Autobiography: New Critical Idiom. New York: Routledge.

Baker, M. (1992). In Other Words: A Course Book on Translation. New York: Routledge. https://doi.org/10.4324/9780203327579

Bassnet, S. (1991). Translation Studies. London and New York: Routledge.

Beaugrande, R., \& Dressler, W. (1981). Introduction to text linguistics. Burnt Mill, Harlow, Essex, UK: Longman Group Limited, Longman House.

Bell, R. (1991). Translation and Translating: Theory and Practice. London and New York: Longman.

Bennet, M. J. (1998). Overcoming the golden rule: Sympathy and empathy. In B. Milton (Ed.), Basic concepts of intercultural communication (pp. 191-215). US: Intercultural Press.

Boushaba, S. (1988). An Analytical Study of Some Problems of Literary Translation: A Study of Two Arabic Translations of K. Gibran's The Prophet. Published Ph. D. The University of Salford, UK.

Carbonell, O. (1996). The Exotic space of cultural translation. In R. Alvarez \& M. C. Vidal (Eds.), Translation, power, subversion (pp. 79-98). Philadelphia: Multilingual Matters.

Carter, R. (1998). Vocabulary: Applied Linguistics Perspectives (2nd ed.). London and New York: Routledge. https://doi.org/10.4324/9780203270110

Chenje, A. (1965). Arabic: Its significance and place in the Arab-Muslim society. Middle East Journal, 19 , 450-459.

Cohen, R. (1987). Problems if Intercultural Communication in Egyptian-American Diplomatic Relations. International Journal of Intercultural Relation, 11, 29-49. https://doi.org/10.1016/0147-1767(87)90030-7

Derrida, J. (1980): Writing and difference. USA: Chicago: The University of Chicago Press.

Eagleton, T. (1996). Literary theory. London: Blackwell.

Erikson, A. (2009). Identity, Language and Culture in Eva Hoffman's Lost in Translation. Sweden: Mid Sweden University.

Faiq, S. (2004). Cultural Encounters in Translation from Arabic (1st ed.). Toronto: Multilingual Matters LTD.

Geertz, C. (1973). The interpretation of culture. U.S.A., Basic Books. 
Gorjan, Z. (1970). On Translating Joyce's Ulysses. In J. Holmes (Ed.), The Nature of Translation: Essays on the theory and practice of literary translation (pp. 201-207). The Hague and Paris: Mouton.

Hatim, B., \& Mason, I. (1990). Discourse and the translator. London and New York: Longman.

Hymes, D. (1972). Models of interaction of language and social life. In J. J. Gumperz \& D. Hymes (Eds.), Direction in Sociolinguistics: The Ethnography of Communication (pp. 35-71). New York and Oxford: Basil Blackwell.

Jacobson, R. (1959). On linguistic aspects of translation. On Translation, 3, 30-39. https://doi.org/10.4159/harvard.9780674731615.c18

Labov, W. (1972). Sociolinguistic Patterns. Philadelphia: University of Pennsylvania Press.

Lejeune, P. (1989). The Autobiographical Pact on Autobiography. Minneapolis: USA: University of Minnesota.

Mahasneh, A. (2016). Arabic language and emotiveness's translation. International Journal of Social Science and Humanities, 6(4). https://doi.org/10.7763/IJSSH.2016.V6.656

Mesthrie, R., Swann, J., Deumert, A., \& Leap, W. (2000). Introducing sociolinguistics. Edinburg: Edinburg University Press.

Nazzal, A. (2012). Translation as an intercultural communication encounter. A deconstructive approach. Arab World English Journal, 3(1).

Nazzal, A. (2017). A preliminary Study of the Translation of English Idiomatic/Formulaic Expressions by ESL/EFL Students: As Marked and Non-Canonical Forms. International Journal on Studies in English Language and Literature, 5(1), 1-12.

Newmark, P. (1981). A Text Book of Translation. New York: Prentice Hall.

Reynolds, D. (2001). Interpreting the Self: Autobiography in the Arabic Literary Tradition. Berkeley: University of California Press.

Shamasneh, K. (2016). Analysis of the Translation Strategies of Barghouti's Autobiography I Saw Ramallah. Unpublished M.A. Thesis. Nablus: An-Najah National University.

Suleiman, M., \& Dweik, B. (2013). Problems Encountered in Translating Cultural Expressions from Arabic into English. International Journal of English Linguistics.

Taylor, K. (2014). Autobiographical Translation: Issues of Faithfulness in Reimaging from Source to Target Text, Using Cronaca Familiare as a Basis for Analysis. Academia.

Teilanyo, D. (2007). Culture in translation: The example of J. P. Clark's The Ozidi Saga. Babel, 53, 1-21.

Whorf, B. (1956). Science and linguistics. In J. B. Carroll (Ed.), Language, thought, and reality: The selected writing of Benjamin Lee Whorf (pp. 207-219). Cambridge Mass: The MIT Press.

\section{Copyrights}

Copyright for this article is retained by the author, with first publication rights granted to the journal.

This is an open-access article distributed under the terms and conditions of the Creative Commons Attribution license (http://creativecommons.org/licenses/by/4.0/). 